\title{
An Empirical Analysis on the Exchange Rate Changes' Relationships between Hong Kong Dollar and Four Major Currencies
}

\author{
Yufeng HUANG \\ Department of Economics \\ University of Macau, UM \\ Macau, China \\ yufengh2013@163.com
}

\author{
Chi Kit NG \\ Department of Economics \\ University of Macau, UM \\ Macau, China \\ mb75618@connect.umac.mo
}

\begin{abstract}
In order to deeply understand the important influence factors of the exchange rate changes of Hong Kong dollar, the methods of correlation analysis, principal component analysis, multiple regression and wavelet analysis are used to analyze the topic of this paper, based on the exchange rate data for five currencies from 2015 to 2017. Some original results are revealed in this study: the general change of four major currencies (USD, JPY, EUR and GBP) was a consequence of the interaction among these currencies; the exchange rates of HKD always changed with the general change of the four currencies; the time series of day-by-day exchange rates for both of the USD and HKD presented a noteworthy periodical change with a time duration about 460-550 days; and the change of HKD exchange rates kept in step with one of USD exchange rate timely; the time span of the noteworthy variation period showed a change trend of gradual augment with a small extent; in the meantime, JPY and EUR also affected the exchange rate changes of HKD to a certain extent. The response relationships of HKD to four currencies were tied closely to the current linked exchange rate system in Hong Kong.
\end{abstract}

Keywords - Hong Kong dollar (HKD); exchange rate change; principal component analysis; multiple regression; wavelet analysis; American dollar (USD)

\section{INTRODUCTION}

Hong Kong is a special administrative region (SAR) of China in which the characteristics of western cultural and social system are maintained. But the execution of the system of "one country two systems" endowed Hong Kong an autonomous jurisdiction of high degree since its handover to China. As a ligament connecting China Yuan (CNY) and international money market, Hong Kong Dollar (HKD) once played an important role in economic development of China and Asia. So the fluctuation and trend changes of exchange rate for HKD are noteworthy problems.

Researches about the exchange rate for HKD mainly in the past kept a watchful eye on the aspects such as linked exchange rate system and the relations between HKD and CNY. The exchange rate of HKD has been linked up with USD since 1983. Meanwhile, the toleration of Hong Kong to the free fluxion of international capitals promoted it to rapidly become the financial center of the Far East [1]. But with its return to
China in 1997, Hong Kong's relations with Chinese mainland in economy and trade were being strengthened, leading to the economic fusion of Hong Kong and Chinese mainland. Then the integration of HKD and CNY become a fierily discussed topic for a time. The six linkage mechanisms between CNY and HKD were put forward in 2002 based on the economic principle of exchange rates. And it was believed that CNY would finally win the leading role in the linkage fluctuation of exchange rates between the two currencies [2]. However, it is a coincidence that the change trend of exchange rates for HKD firstly presented an obvious deviation with one of USD in November 2004, which touched the sensitive nerves of academia. Through investigating the incident, the expecting influence of CNY exchange rate changes on the exchange rate of HKD was experientially testified. And some scholars thought that the incident implied the gradual differentiation between Hong Kong and America and the gradual convergence of Hong Kong with Chinese mainland in economic change cycle [3]. Some researchers proposed that the linked exchange rate system in Hong Kong should be reformed and lead in the influence element of CNY. And the exchange rates of HKD should be linked up with CNY at a proper time in the future, in order to realize the fusion of the two currencies under the background of the unceasing internationalization of CNY [4]. Influenced by this thought, the change trend of exchange rates for HKD was once considered as the manifestation of the economic fusion between Hong Kong and Chinese mainland [5].

However, some scholars doubt if the relationships of exchange rates between HKD and USD is weakening, and if the synergistic effect of Hong Kong and Chinese mainland in economic development has been strengthened. Some persons found that only eastern coastal areas of Chinese mainland were consistent with Hong Kong in the price of commodities and economic growth [6]. The results of correlation analysis by stages showed that the degree of correlation for economic growth rates between the two regions was lower as a whole [7]. Whereas, the synergy level of economic cycles between the two regions increased with the fusion in economy and trade [8]. But if American economy was regarded as an intermediate variable to examine and weigh, the economic cooperativity between Hong Kong and Chinese mainland was decreased to a 
low value of overall level [9]. Meanwhile, some researchers testified that the fluctuation of currency exchange rates for Hong Kong and its prime trade partners had obvious synergistic effects from the perspective of international balance of payment [10]. So, others opposed the integration of CNY and HKD, and proposed that the internationalization of HKD should be reinforced and be linked up with a basket of currencies (Special Drawing Rights) in future, in order to maintain the stability of HKD and Hong Kong's role as international financial center. Moreover, Chinese mainland should promote HKD to be a competitive currency of surpassing sovereignty [11].

Overall, with respect to the fluctuation of exchange rates for HKD, current researches mainly focus on analyzing the currency system and interpreting the relevant empirical phenomenon. The demonstration research with quantitative analysis is scarce. And few scholars conduct the quantitative researches about the influences of other currencies except for $\mathrm{CNY}$ on the exchange rates of HKD. In view of the abovementioned research status, the time series data about the exchange rates with converting HKD and four major currencies into the CNY were collected to analyze the influences of the major currencies on the exchange rate changes of HKD in this paper.

\section{DATA AND RESEARCH SCHEME}

\section{A. Data and methods}

According to the ranking of Gross Domestic Product for various countries in the world during 2015-2017, USA, China, Japan, Germany, Britain and France are the top six economic entities. The currencies used by these economic entities include USD, CNY, JPY, EUR and GBP. Among them, the range of fluctuation changes for EUR is the least while CNY taking second place (proved by relative rates of change).

In terms of the requirement for the topic of this paper, the used exchange rate data are based on the criterion of CNY parities with real-time exchange rates. The original data are day-by-day exchange rates (including five currencies, i.e. HKD, USD, JPY, EUR and GBP) published by Bank of China from 19, December 2014 to 19, December 2017.

In order to eliminate the unfavourable influences of a few of day-by-day exchange rate data with overlarge deviation, the original day-by-day data sequence was converted into the time series of the average values for ten days in sequence. Based on the time series data, several statistical methods included correlation analysis; principal component analysis and multiple regressions are used to implement this analytical investigation. But day-by-day exchange rate data are firsthand applied to wavelet analysis method in this paper.

\section{B. Research scheme}

Four aforesaid statistical methods are synthetically used to analyze the topic of this paper.

Firstly, the methods of principal component analysis and correlation analysis are combined to preliminarily analyze the correlation between the change of HKD exchange rates and the general four currencies (USD, EUR, JPY and GBP). Based on time series data of the exchange rates for the four currencies, the method of principal component analysis is used to simplify the complicated changes of the four main currencies' varying with time. And the principal component factors of the changes for main currencies environment during 2015-2017 are extracted. Then the method of correlation analysis is applied to analyze the correlation coefficients between HKD exchange rate and principal component factors.

Secondly, the method of regression analysis is used to quantitatively analyze the relationships between the exchange rates of HKD and the main currencies. Here, a time period of a specimen for any used currency variables refers to a period of ten days. And symbol $t$ is defined as an integer variable expressing a sequence number for a period of ten days. The exchange rates of each currency for the time periods ranked as serial number $t, t-1, t-2$ are all regarded as independent variables, which are selected to build a regression equation with the dependent variable of the exchange rate for HKD ranked as serial number $t$.

Thirdly, wavelet analysis method [12] is a powerful diagnostic tool directing at temporal frequencies, being especially suitable for disposing nonstationary signals. It was applied to extracting the variation signals of time series for prime currencies in this paper. Through this analysis method, the periodism characteristics of the exchange rates for some currencies are expected to acquire.

\section{RESULTS AND THEIR PRELIMINARY ANALYSIS}

\section{A. The elementary statistical characteristics for five currencies}

The basic statistical indicators for five currencies during the analyzed three years are listed in table 1 . Thereinto, coefficient of variation is a ratio value of the standard deviation to the average value for a group of samples of an identical variable, a statistical index being suitable for comparing average amplitude of variation among several variables. The table shows that HKD is a currency with the least amplitude of relative variation for the exchange rates among the five currencies, while USD taking second. And JPY has the biggest relative variation.

TABLE I. THE BASIC ST ATISTICS FOR FIVE CURRENCIES FROM 2015 TO 2017 BASED ON DAILY DATA

\begin{tabular}{|c|cccc|}
\hline $\begin{array}{c}\text { Name of } \\
\text { currency }\end{array}$ & Mean & median & std. deviation & $\begin{array}{c}\text { coefficient of } \\
\text { variation }\end{array}$ \\
\hline HKD & 0.8424 & 0.8454 & 0.0329 & 0.0390 \\
USD & 6.5437 & 6.5700 & 0.2619 & 0.0400 \\
GBP & 9.0826 & 8.9245 & 0.44919 & 0.0494 \\
EUR & 7.2943 & 7.3276 & 0.3384 & 0.0464 \\
JPY & 0.0577 & 0.0590 & 0.0049 & 0.0851 \\
\hline
\end{tabular}


B. The standardizing and normalizing of the exchange rate samples for five currency variables

- In view of the different units and dimensions for various kinds of currencies, the samples of all variables are firstly standardized. After implementing the standardization, the correlation coefficients of exchange rates between HKD and other currencies are calculated and listed in Table2.

TABLE II. THE CORRELATION COEFFICIENTS OF EXCHANGE RATE VARIABLES BETWEEN HKD AND OTHER CURRENCIES AFTER ST ANDARDIZING AND NORMALIZING

\begin{tabular}{|c|c|c|c|c|c|c|c|c|c|c|c|c|c|c|}
\hline & $\mathrm{USD}(t)$ & $\mathrm{JPY}(t)$ & $\mathrm{GBP}(t)$ & $\operatorname{EUR}(t)$ & $\mathrm{HKD}(t-1)$ & $\mathrm{HKD}(t-2)$ & $\mathrm{USD}(t-1)$ & $\mathrm{USD}(t-2)$ & $\mathrm{JPY}(t-1)$ & $J P Y(t-2)$ & $\mathrm{GBP}(t-1)$ & $\operatorname{GBP}(t-2)$ & $\operatorname{EUR}(t-1)$ & $\operatorname{EUR}(t-2)$ \\
\hline standardized & $0.990^{* *}$ & $0.84^{* *}$ & $-0.737^{* *}$ & $0.667^{* *}$ & $0.992^{* *}$ & $0.98^{* *}$ & $0.977^{* *}$ & $0.953^{* *}$ & $0.843^{* *}$ & $0.844^{* *}$ & $-0.725^{* *}$ & $-0.719^{* *}$ & $0.639^{* * *}$ & $0.604^{* *}$ \\
\hline $\begin{array}{l}\text { Standardized } \\
+ \text { normalized }\end{array}$ & $0.970^{* *}$ & $0.742^{* * *}$ & $-0.699^{* *}$ & $0.553^{* * *}$ & $0.968^{* * *}$ & $0.932^{* *}$ & $0.94^{* * *}$ & $0.910^{* * *}$ & $0.751^{* *}$ & $0.759^{* *}$ & $-0.668^{* *}$ & $-0.654^{* *}$ & $0.539^{* * *}$ & $0.531^{* * *}$ \\
\hline
\end{tabular}

Note: “( $t$-2)”,”(t-1)” and ”( $(t)$ " are the identifyings of three continuous time periods of every ten days; ${ }^{* *}$ expresses the significance level $P=0.000$.

- The method of multiple regression analysis requires the variables samples to be normally distributed. But the distributions of the samples for most of currency variables have obvious deviations with normal distribution in this paper, among which the variable of USD has the greatest deviation. So the samples of above standardized variables are further normalized here. After implementing the normalization, the correlation coefficients of exchange rates between HKD and other currencies are calculated and listed in Table2.

(a)

Zscore(us1)

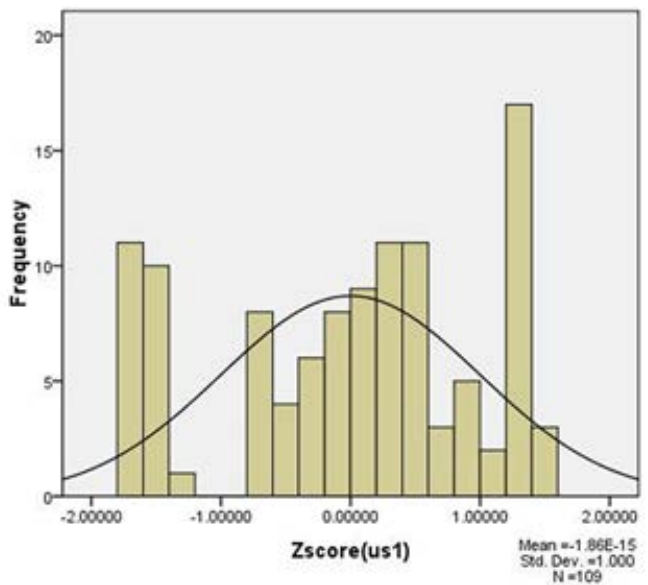

- According to Table2, the correlation coefficients between any two exchange rate variables changed in some degrees after normalization. But the significance level of the correlation between any two variables stays original level. That is to say, the variation tendencies of the variable sample sequences and the relationships among variables remain the same after implementing standardization and normalization. Fig.1 showed the samples frequency distributions of the standardized exchange rate variable for USD before and after normalization. Normal Score of Zus1 using Blom's Formula

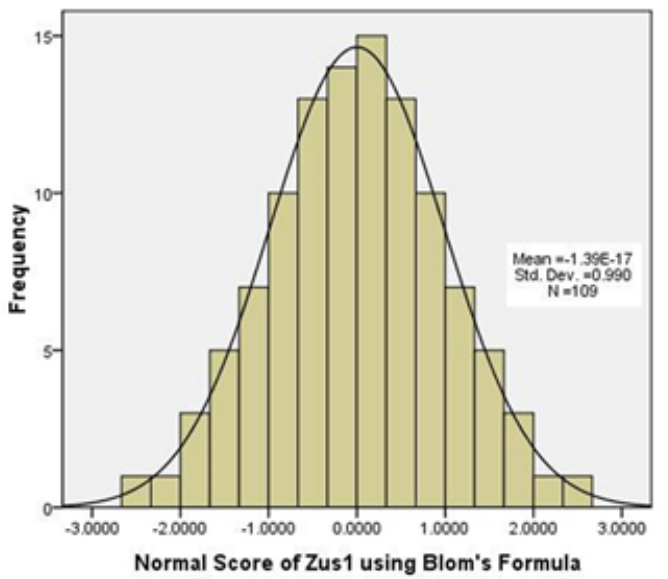

Fig. 1. The samples frequency distributions of the standardized exchange rate variable for USD before and after normalization (a, before normalization; b, after normalization)

C. The principle component of the changes for exchange rates environment of several main currencies

- The exchange rates' total changes for USD, EUR, GBP and JPY are regarded as the environment variables field affecting the variation of the exchange rate for HKD in this paper. Based on the standardized and normalized variables sample sequences, the method of principle component analysis is used to analyze the change of exchange rates field for main several currencies during the three years. As showed in Table3, a dominant principle component was extracted to explain the total variance of the changes for exchange rates environment field with interpretation degree of 72.55 percent of total variance. The principle 
component is composed of the variation information for exchange rates of four currencies, among which USD, EUR, GBP and JPY account respectively for $79.0 \%, 63.5 \%, 67.3 \%$ and $80.3 \%$ of total variation information.

TABLE III. THE DEGREES FOR THE EXTRACTED PRINCIPLE COMPONENTSTO EXPLAIN THE VARIANCE OF ORIGINAL VARIABLES FIELD

\begin{tabular}{|c|ccc|ccc|}
\hline \multirow{2}{*}{$\begin{array}{c}\text { Com- } \\
\text { ponent }\end{array}$} & \multicolumn{3}{|c|}{ Initial Eigenvalue } & \multicolumn{3}{|c|}{$\begin{array}{c}\text { Extraction sums of } \\
\text { squared loading }\end{array}$} \\
\cline { 2 - 7 } & total & $\begin{array}{c}\% \\
\text { of variance }\end{array}$ & $\begin{array}{c}\text { Cumulative } \\
\%\end{array}$ & total & $\begin{array}{c}\% \\
\text { of variance }\end{array}$ & $\begin{array}{c}\text { Cumulative } \\
\%\end{array}$ \\
\hline 1 & 2.902 & 72.555 & 72.555 & 2.902 & 72.555 & 72.555 \\
2 & 0.548 & 13.699 & 86.257 & & & \\
3 & 0.313 & 7.82 & 94.075 & & & \\
4 & 0.237 & 5.925 & 100 & & & \\
\hline
\end{tabular}

TABLE IV. THE COEFFICIENTS VALUES OF THE NORMALIZED VARIABLES FOR FOUR CURRENCIES TO INFLUENCE THE PRINCIPLE COMPONENT

\begin{tabular}{|l|llll|}
\hline & USD & EUR & GBP & JPY \\
\hline coefficient & 0.306 & 0.275 & -0.283 & 0.309 \\
\hline
\end{tabular}

According to Table4, the absolute values of the coefficients of four currencies' exchange rates to influence the principle component are all the same order of magnitude. It is thus clear that the total change of exchange rates environment field resulted from the mutual effects and synergy of the main four currencies, whose primary and secondary impacts were not notable in distinction.

D. The correlation between the exchange rates of HKD and the principle component for four currencies

- The correlation coefficient between the exchange rate of HKD and above first principle component is 0.884 , which was verified for statistics with the significance level $P=0.001$. This means that the changes of exchange rates for HKD are outstandingly affected by the variation of exchange rates for main several currencies.

E. The quantitative relationships of exchange rates changes between HKD and main several currencies

To quantify the different influence of main currencies on HKD, multiple regression was applied to define the quantified relationships between HKD and other currencies. And the explanatory variables of exchange rates were selected based on correlation analysis.

- Correlation coefficients between HDK exchange rate and other currencies

Here, symbol $t$ is defined as an integer variable expressing a sequence number for a period of ten days. According to the results of correlation analysis (the table omitted), the correlation between the exchange rate of HKD for a ten-day period with sequence number $t$ and all variables (the exchange rates of USD, EUR, GBP and JPY for the ten-days periods with sequence number $t, t-1$ and $t$-2 respectively) have passed the test of significance level $P=0.001$. Among them, HKD's correlation coefficients with USD exchange rate for the ten-days periods with sequence number $t-1$ and $t-2$ (0.960 and 0.920 ) are close to the correlation coefficients with HKD exchange rate itself for the ten-days periods with sequence number $t-1$ and $t-2$ (0.968 and 0.932). And HKD exchange rates' correlation coefficients with JPY reach the maximum values of 0.759 and 0.751 , while the coefficients with EUR is 0.553 in the ten-day period with sequence number $t$ and 0.539 in the ten-day period with sequence number $t-1$. But the correlation coefficients with GBP's exchange rate are negative, as -0.699 in the ten-day period with sequence number $t$ and -0.599 in the ten-day period with $t-1$.

- Comprehensive influences of currency exchange rate variables on HKD exchange rate of the ten-day period with sequence number $t$

Here, the symbol $t$ is regarded as focused current time period. Taking into consideration the comprehensive influences of multiple currencies with different time periods on HKD exchange rate of the ten-day period with sequence number $t$, the best regression equation was built up (expressed as Model1; see Table5, Table6, Table7 and Fig.2). Thereinto, these nominated multiple currencies with different time periods include USD's exchange rates of the ten-day periods with sequence number $t-1, t$, and GBP's, EUR's exchange rates of the ten-day periods with sequence number $t-1$, and JPY's exchange rate of the tenday periods with sequence number $t$.

TABLE V. THE MAJOR PARAMETER VALUES OF TWO REGRESSIONS EQUATIONS ABOUT THE EXCHANGE RATE VARIABLE OF HKD

\begin{tabular}{|l|ll|}
\hline & Model1 & Model2 \\
\hline R & 0.997 & 0.997 \\
R square & 0.994 & 0.994 \\
Adjust R square & 0.994 & 0.994 \\
Std.Error & 0.07679 & 0.07952 \\
R square change & 0.994 & 0.994 \\
F change & 3642.70 & 5657.73 \\
df1 & 5 & 3 \\
df2 & 103 & 105 \\
Sig.F change & 0.000 & 0.000 \\
\hline
\end{tabular}

TABLE VI. THE EFFECT TEST OF TWO REGRESSION EQUATIONS ABOUT THE EXCHANGE RATE VARIABLE OF HKD

\begin{tabular}{|l|ll|}
\hline & model1 & model2 \\
\hline explained sum of square & 107.393 & 107.336 \\
residual sum of square & 0.607 & 0.664 \\
total sum of square & 108 & 108 \\
F & 3643.0 & 5658.0 \\
Significance level & 0.000 & 0.000 \\
\hline
\end{tabular}


TABLE VII THE STATISTICAL TEST OF REGRESSION COEFFICIENTS FOR REGRESSION EQUATIONS ABOUT THE EXCHANGE RATE VARIABLE OF HKD FOR THE PERIOD WITH SEQUENCE NUMBER $T$

\begin{tabular}{|l|ll|}
\hline & model1 & model2 \\
\hline $\operatorname{USD}(t)$ & $0.984^{* *}$ & $1.0^{* *}$ \\
$\operatorname{JPY}(t)$ & $0.035^{*}$ & $0.050^{* *}$ \\
$\operatorname{EUR}(t)$ & & $-0.052^{* *}$ \\
$\mathrm{USD}(t-1)$ & $-0.375^{* *}$ & \\
$\operatorname{HKD}(t-1)$ & $0.384^{* *}$ \\
$\operatorname{EUR}(t-1)$ & $-0.024^{*}$ \\
$\operatorname{GBP}(t)$ & & \\
\hline \multicolumn{2}{|c}{ Note: "expresses the significance level $P=0.01 ;$} \\
\hline \multicolumn{2}{|c|}{ "* expresses the significance level $P=0.001}$. \\
\hline
\end{tabular}

The fitting degree $\mathrm{R}^{2}$ value of Model1 is 0.994 , with three nominated variables passing the test of high significance level $(P=0.001)$. Judged by the absolute values of regression coefficients, the influence levels of four currency variables on HKD exchange rate of the ten-day period with sequence number $t$ are ranked as (high to low): USD exchange rate of the ten-day period with sequence number $t$, HKD exchange rate of the ten-day period with sequence number $t-1$, USD exchange rate of the ten-day period with sequence number $t-1$, JPY exchange rate of the ten-day period with sequence number $t$ and EUR exchange rate of the ten-day period with sequence number $t-1$. Among them, USD has the largest influence on HKD exchange rate of current ten-day period, with the impact during two consecutive ten-day periods. Besides, the fact that the obvious influence for HKD exchange rate of the ten-day period with sequence number $t-1$ on that of its next period (with sequence number $t$ ) shows the inter-time period stability of HKDs exchange rate. JPY exchange rate of the ten-day period with sequence number $t$ and EUR exchange rate of the ten-day period with sequence number $t-1$ also have considerable impact on HKD, but both are smaller than USD and HKD itself. Also, HKD appears to be more responsive to JPY than EUR. (a)

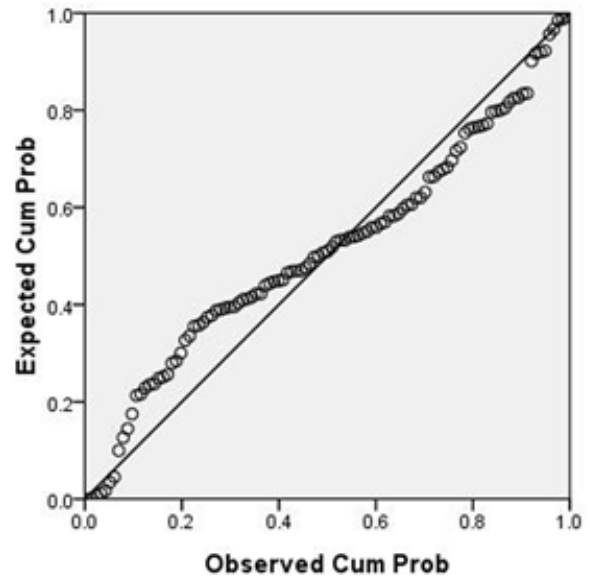

(b)

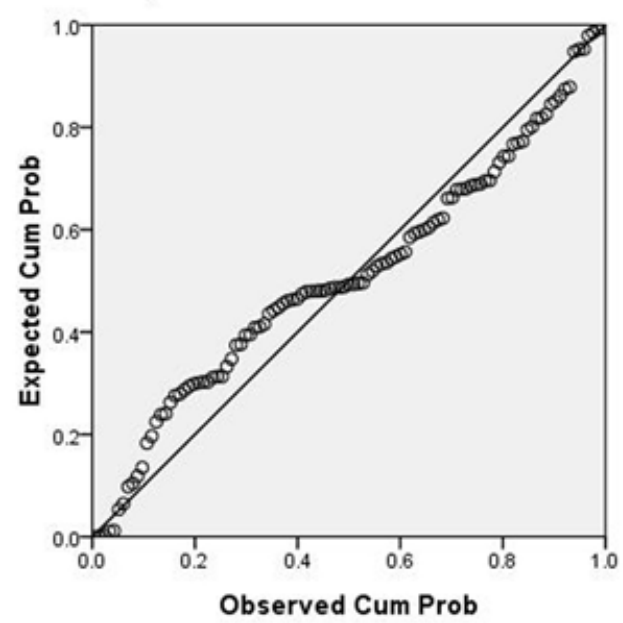

Fig. 2. Fitting Results of Two Regression Equations on HKD Exchange Rate (a, Model1; b, Model2)

- The influences of main currencies' exchange rates on HKD exchange rate during a same ten-day period

As suggested by the regression results (see Table5, Table6, Table7 and Model2 in Fig.2), the exchange rates of USD, JPY and EUR in the ten-day period with sequence number $t$ are positively correlated to the HKD's exchange rate of the same ten-day period $t$. Among them, USD has the largest regression coefficient, which is 20 times of that of other currencies in absolute values. This result shows that HKD has highest responsive level to USD during the current ten-day period. JPY and EUR both have much smaller influence on HKD exchange rate in the same period. In the above-mentioned 2 regression equations, the exchange rate of GBP shows insignificant impact on that of HKD.

\section{F. Periodic fluctuation of HKD exchange rate}

- Based on wavelet analysis of HKD and USD exchange rates of three years following time 
sequence, results can be found as in Fig.3. The fluctuations of the two currencies are prone to be periodical. The wavelet analysis results of USD and HKD are highly similar. About two and half waves of exchange rates for the two currencies are found out during the analyzed three years. And the length of a credible variation period presents a gradual increase trend with a small extent in the whole analyzed period. The variation period of the obtained waves with maintaining constant statistical significance is about 460-550 days (the significance level $P=0.05$ ).
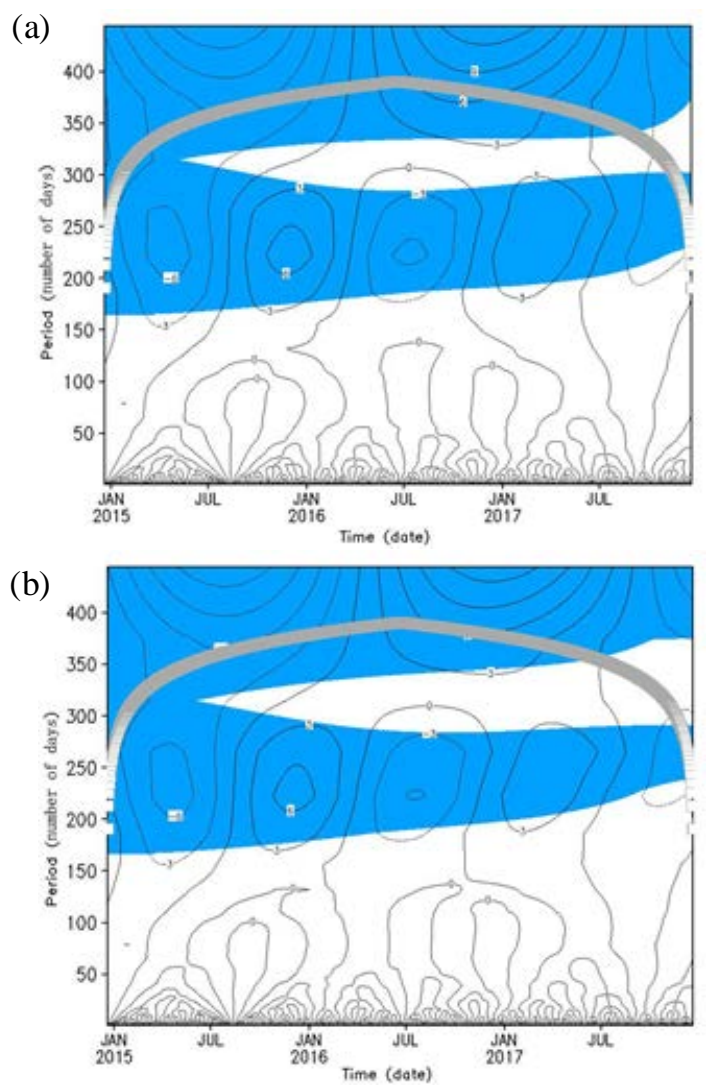

Fig. 3. The wavelet analysis results of daily exchange rates for two currencies during analyzed three years

(a, HKD; b, USD; shadow region expresses the significance level $P=0.05$; the results over the gray thick line is incredible)

\section{DISCUSSION}

According to the principal component analysis, the environmental change caused by main currencies is the major factor influencing HKD exchange rate changes. The result shows that the general changes of exchange rates from 2015 to 2017 were jointly influenced by four main currencies, instead of being dominated by one currency. Thereinto, the influence level of USD and JPY are similar, which is slightly higher than that of EUR and GBP. But the correlation coefficient of HKD's exchange rate and the first principal component of 4 main currencies is as high as 0.884 (significance level $\mathrm{P}=0.001$ ), which suggests a close relationship between HKD's exchange rate and the international monetary market.

The two regression equations (Model1 and Model2) are practical and functional. If the current ten-day period (or the previous ten-day period) of the USD's exchange rate is used to simulate the HKD's exchange rate, the fitting degree to HKD's exchange rate of current ten-day period is 0.941 (or 0.884). But when multiple variables are applied, the fitting degree falls to 0.994 and 0.997 (significantly improved). In particular, the result of Model1 is acquired on condition that the variation coefficients of the samples for other 4 currencies are all bigger than that of HKD (see Table1). The regression analysis shows that Model1 mainly presents the influence of multiple currencies on HKD, with USD being the dominant one. Model 2 shows the relationships between multiple currencies' exchanges rates and that of HKD during current ten-day period, which suggests HKD is quite sensitive to the changes of USD exchange rate, matching Hong Kong's current exchange rate system [9].

HKD's exchange rate has a highly positive correlation with the principal component of the changes for 4 main currencies' exchanges rates. While the multiple regression analysis indicates that the USD exchange rate is a dominant factor to HKD. The two conclusions don't conflict with each other. The correlation coefficient of HKD exchange rate with the above principal component is 0.884 , while that with USD reaches 0.970 . Meanwhile, the correlation between USD and JPY or EUR reaches the significance level $p=0.001$ too, only the significance level of the correlation between USD and GBP is $\mathrm{p}=0.05$.

Wavelet analysis not only reveals the periodism characteristics of fluctuation changes of USD and HKD exchange rates, but also confirms the key character that HKD's fluctuation closely follows that of USD. The analyzed-result graphs of these two currencies are very similar with almost the same lengths of their variation periods. With closer observations, it's not difficult to spot there are 1 to 2 days of delay on HKD fluctuation period to that of USD. This is a strong proof that USD and HKD are highly positively correlated time sequences.

The results of the empirical analysis in this article have a rationalization to a great extent. The fluctuation of $\mathrm{HKD}$ exchange rate is an indicator of Hong Kong's economic conditions and business cycles, as well as a comprehensive expression of Hong Kong's linkage with currency, financial markets and actual economy-trade interflow of different regions. Relevant informations show that USA, Japan, Germany, UK and France all ranked as the top ten trade partners of Hong Kong. USA and Japan in particular, are Hong Kong's first and second largest trade partners (based on import/export scale) [13].

\section{CONCLUSION}

The exchange rate changes of USD, JPY, EUR and GBP are not dominated by one currency, instead, a consequence of the interaction among these currencies. Thereinto, USD and JPY have a similar influence level, which is slightly 
higher than that of EUR and GBP. The fluctuation of HKD exchange rate is a result of its responding to the cooperation and interactions of multiple currencies in international financial market, which is also closely related to the active Linked Exchange Rate System in Hong Kong.

HKD is very sensitive to the changes of USD exchange rate. Consequently, USD appears to be a major factor influencing HKD's exchange rate fluctuation. Specifically speaking, HKD exchange rate of current ten-day period is highly influenced by that of USD for current and previous ten-day periods. Meanwhile, HKD is quite sensitive to JPY exchange rate variation timely. However, there is an obvious delay of EUR's influence on HKD. Incidentally, GBP shows no significant influence on HKD's exchange rate.

The time series of day-by-day exchange rates for USD and HKD presented a noteworthy periodical change with time duration about 460-550 days. And the periodical change of HKD exchange rate kept in step with one of exchange rate for USD timely. Moreover, the length of the credible variation period showed a gradual increase trend with a small extent during the analyzed period of three years. The two built regression models and the revealed periodical change features of HKD exchange rate should be very practical in predicting HKD's exchange rate.

\section{REFERENCES}

[1] CHEN Yixin, "Future trend of the linked exchange rate system in Hong Kong under the background of RMB internationalization,” China Price, 2016, (5):20-22. (in Chinese)
[2] LI Xindan and FU Hao, "Transmission mechanism analysis of the exchange-rates interaction effect between China Yuan and ThHKD,” Finance Research, 2002, (3):123-129. (in Chinese)

[3] BA Shusong and Huang Shaoming, "Why the interest rates of US dollar and HK dollar fluctuated differently," Finance \& Trade Economics,2005, (8):10-14. (in Chinese)

[4] LIU Ying, "The relationship between RMB and HK dollar against the background of Economic Integration," Asia-Pacific Economic Review,2004, (4):9-11. (in Chinese)

[5] WANG Wei-an, “A useful attempt in China's monetary integration research,” Finance \& Trade Economics, 2004, (8):91-91. (in Chinese)

[6] Tsang S K, "Optimum Currency Area for Mainland China and Hong Kong? Variance and Shocks Decomposition Tests," Foreign Literature, 2012. (in English)

[7] LI Xindan and HONG Liang, "The analysis methods evaluation of exchange rate relationship between RMB and HK dollar,” Financial Perspectives Journal, 2003, (4):42-47. (in Chinese)

[8] Genberg H and Liu L G, “Jin X. Hong Kong's Economic Integration and Business Cycle Synchronisation with Mainland China and the US,” Journal of the A merican Dental Association, 2006, 137(1):44-53. (in English)

[9] CHEN Xiaofan, "Regine dependence synchronization between mainland China and Hong Kong and the influence from US,” World Economic Study, 2007, (9):82-85. (in Chinese)

[10] LIN Jiang and XIA Yusong, "External factors affecting the exchange rate of Hong Kong dollar: the impacts coming from other currencies," Journal of Sun Yatsen University, 2004, 44(1):84-91. (in Chinese)

[11] XIAO Geng, "The reason why Hong Kong became an international financial center,” China Finance, 2017, (13):15-18. (in Chinese)

[12] Ingrid. Daubechies. Ten Lectures on Wavelets. the Society for Industrial and Applied Mathematics, Philadelphia, Pennsylvania, 1992:18-22. (in English)

[13] Docin.com. Principal trade partners of Hong Kong. http://www.docin.com/touch_new/preview_new.do?id=656595600 (in Chinese) 